\title{
Automatic Rack Moving by Reacting to the Sunlight
}

\author{
Masayuki Tajima ${ }^{\mathrm{a}}$, Takumi Saruhashi ${ }^{\mathrm{a}}$, Seiichi Serikawa ${ }^{\mathrm{b}}$, Yuhki Kitazono ${ }^{\mathrm{a},{ }^{*}}$ \\ ${ }^{a}$ National Institute of Technology, Kitakyushu College, 5-20-1 Shii, Kokuraminamiku, Kitakyushu, Fukuoka, 802-0985 \\ Japan \\ ${ }^{\mathrm{b}}$ Kyushu Institute of Technology, 1-1, Sensui-cho, Tobata, Kitakyushu, Fukuoka, 804-8550 Japan \\ *Corresponding Author: kitazono@kct.ac.jp
}

\begin{abstract}
When the laundry hang up, it is difficult to put the laundry in a high position, and how to dry is different by the degree to which the sun shines. This paper describes a machine to solve those problems. When you feel that you want to dry the laundry, you adjust to the position of the pole. Anyone can easily operate the device because it is only a push-button switch. As well, it may be difficult to dry because the sunlight does not hit in the laundry, the light sensor automatically adjusts the part of the pole to the sunlight. We hope that this machine will be useful for your daily life.
\end{abstract}

Keywords: Life support device, Light sensor, Servomotor

\section{Introduction}

Laundry is indispensable to a daily life and it should be burdensome in our life. For example, it takes a long time because laundry does not dry fast, when there is a pole at the high position, hanging out the washing. From of "Questionnaire on the 1st Household Affairs in the 2nd Phase" conducted by "Mujirushiryouhinnoie" during the period from November 3, to 9 2008, the results were shown an in Fig.1, 2, 3 was obtained. More than half of people are washing almost every day in Fig.1, and about 40\% people answered that drying work is normal / burdensome. In Fig. 2 one of the reasons that children and the elderly particularly feel burden is they must place the laundry many times on a pole at a high position. It takes long time in the average washing time in one week shown in Fig.3. There is a device that can be automatically and easily adjusted in height (Panasonic's indoor clothes drying unit "Hoshihime Sama"), and the device has many merits. However, $70 \%$ of the places where the laundry is done are outdoors such as a veranda and a garden shown in Fig. 4. That is, there are disadvantages to become damp and hard to dry indoors. The sun drying has a sterilization effect by lasting ultraviolet rays of the sunlight.

Therefore, we take about a device to fully utilize the sunlight in this study. This device rotates the motor from the signal from the distance sensor and adjusts the mechanism of vertical movement using a pulley, thereby the height of the pole is decided. In addition, when using the light sensor and sunlight does not hit the light sensor, drying can be promoted by moving the clothes pole to the position where it drives the servo motor. These can reduce the burden and time concerning the laundry mentioned earlier.

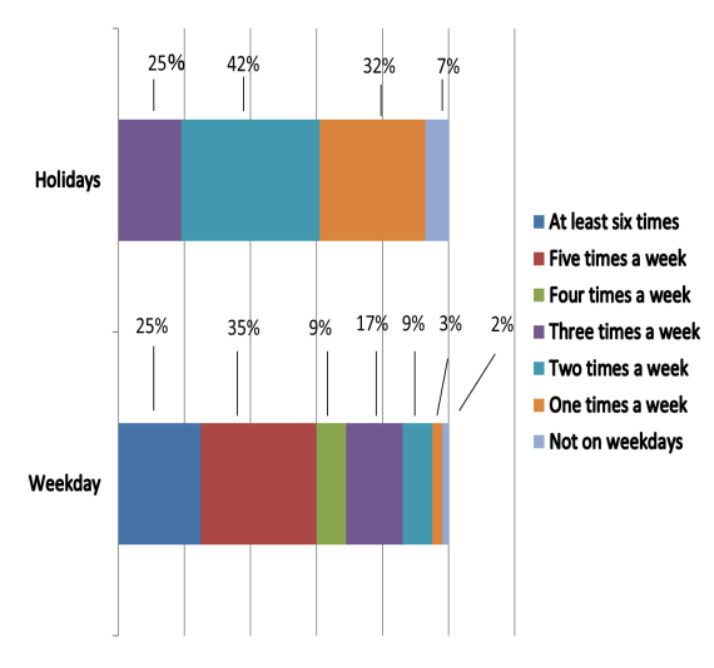

Fig.1. Frequency of washing 


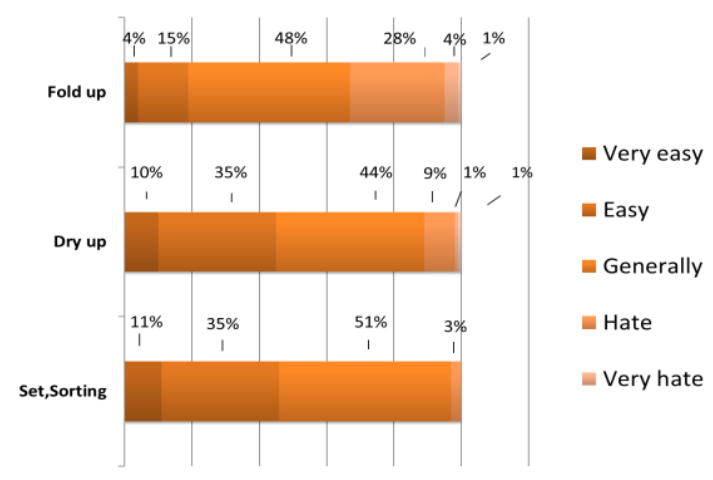

Fig.2. The degree of burden of laundry.

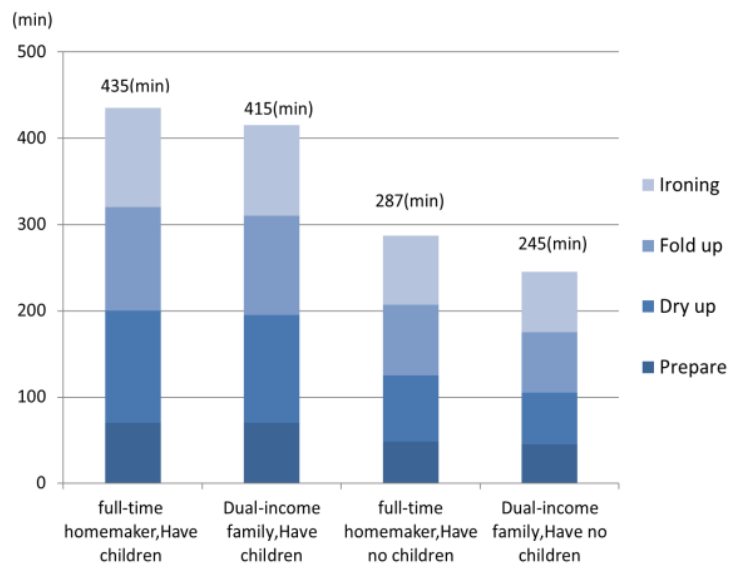

Fig.3. Average washing time of a week.

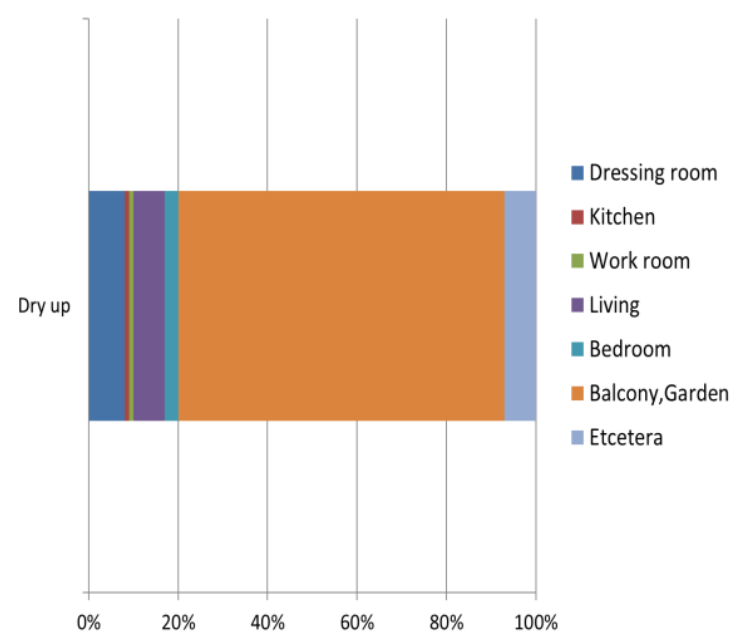

Fig.4. Washing space.

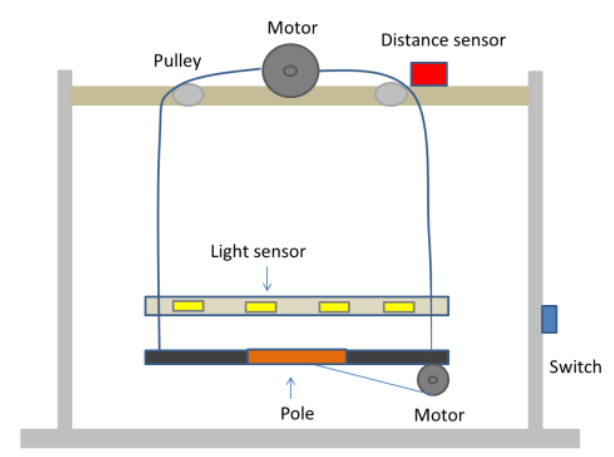

Fig.5. Global image of device

\section{The structure of device}

\subsection{Overview of a device}

The overall image of the device is shown in Fig.5. There are the two general flows of the device. The first is to adjust the height by push button switch. Pressing the push-button switch brings the rod down to the position where Arduino's program, the motor driver makes it easier to place laundry at low level. The second is to use the optical sensor or the distance sensor to move the position of the rod to the place where sunlight hits so that sunlight always hits the laundry. The signal of the light sensor and the distance sensor is sent to Arduino, and the rod is moved so that the laundry strikes the sun by rotating the motor. These two movements reduce the burden on laundry.

\subsection{Mechanism of upward and downward motion}

We explain the system upward and downward. Power conducts from the rotary motion of a servomotor shown in Fig. 6 to the pulley of both ends. We push the switch, and the turn of the servomotor realized through Arduino. In addition, adjusting the height is decided by the value that a distance sensor (ultrasonic sensor) provided it and the height that it is easy to take. We attach a distance sensor to be shown in Fig.10, measure a price of the distance, and regulate height. Movement stops it based on the value that a servomotor works when we push the switch shown in Fig.9, and the distance sensor read. 


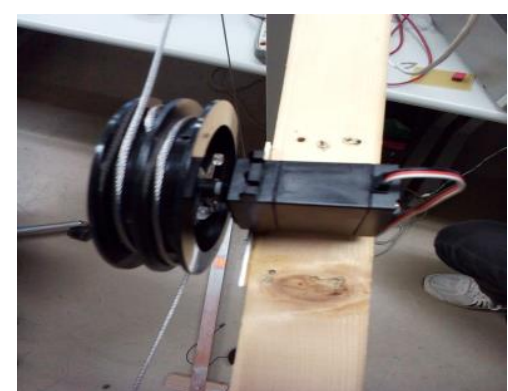

Fig.6. Servomotor.

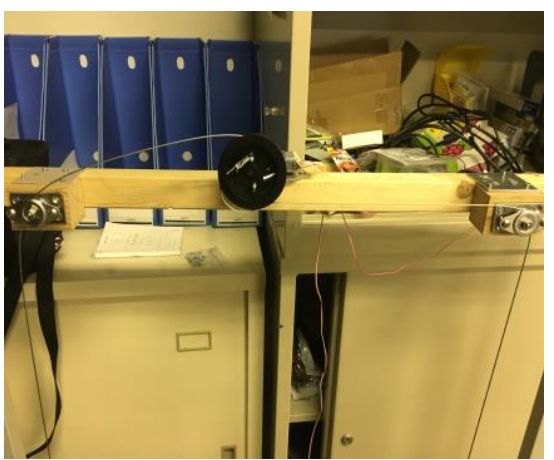

Fig.7. Pulley.

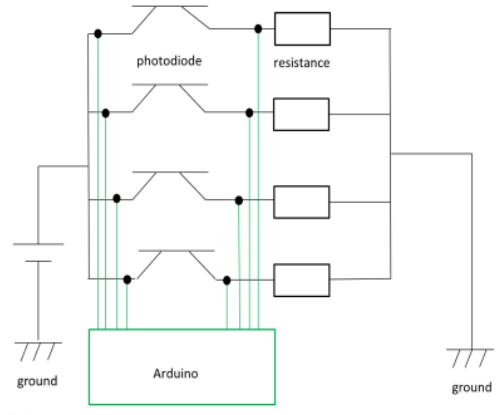

Fig.8. Circuit

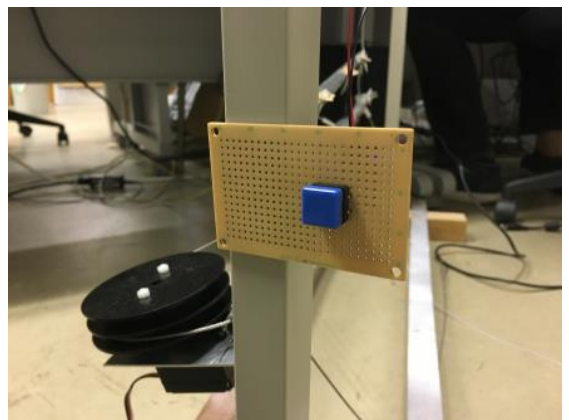

Fig.9. Push-button switch.

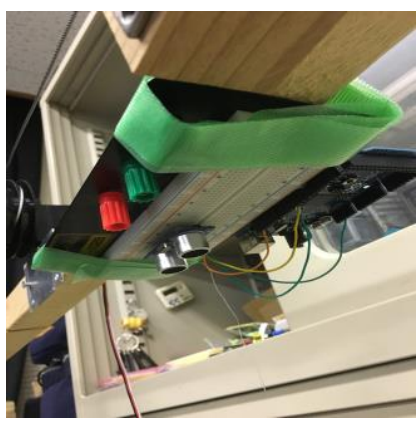

Fig.10. Distance sensor

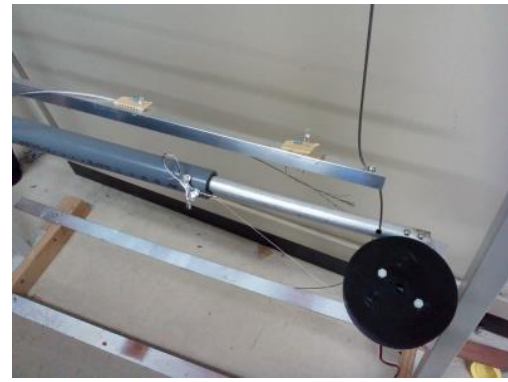

Fig.11. Light sensor

\subsection{Light sensor}

Fig.9 shows the part where the optical sensor (phototransistor) is used. Although some light sensors are lined up but this sensor hits the sunlight, the servomotor does not rotate but stay at a certain position but if nothing is hit by sunlight, the servomotor rotates and move right and left. In addition, the sensor is exposed to sunlight again.

\section{Experiment}

I experimented to see if the device actually functions. Two experiments were conducted. In addition, the experimental method and experimental results were described. In the first experiment, the height was adjusted by pressing the push-button switch. Because of pushing the push-button switch, the servomotor was rotated and the height could be adjusted. The second experiment compared the speed of drying with and without this device. The place to dry the also clothes are the same, and the wet condition of clothes is the same. The light sensor sent the signal normally to Arduino according to how much sunlight was applied and the servomotor rotated. The servomotor stopped operating when the position of the rod moved to the position where sunlight hit again and moved to the position where sunlight hits the light sensor. Therefore, it got dryer faster with more sunlight when using the equipment. 


\section{Summary}

In this research, we created a system to keep laundry on sunlight. This system was able to improve inconvenience such as hard to dry of the laundry and taking in. These improvements will greatly reduce the burden on housework. However, the function of this machine can't be demonstrated in places where sunlight is not always hit. This will be the problem in the future. As well, when it suddenly rains, it will be a machine with better functions.

\section{Acknowledgment}

In case of necessity, click here and insert your acknowledgement text.

\section{References}

(1) http://ns3ns.muji.co.jp/ie/lifestyle/questionnaire/2_01a .html

(2) http://www.o-uccino.jp/article/archive/kurashi/201601 28-sun/ 